\title{
A Diachronic Approach to Web-Based Genres: The Case of the Personal Weblog*
}

\author{
Peter Schildhauer (Halle)
}

\begin{abstract}
This study pursues two related aims: (1) It develops a diachronic approach to web-based genres and explores its potentials and limitations. (2) As a case in point, it uses the genre personal weblog, providing a diachronic description of both recurrent and changing features of the genre. It applies a mixed-methods approach that draws on historical sources and the DIABLOC, a diachronic blog corpus, which spans 15 years from 1997 to 2012 and includes also examples of the very first weblogs. Analyses are selectively extended beyond the surface of blog-pages to their HTML source code. On the basis of corpus material, patterns of genre change such as migration, pattern embedding and genre split are described and embedded into a differentiated model of the development of the personal weblog genre.
\end{abstract}

\section{$1 \quad$ Introduction}

Genre research on the World Wide Web has been compared to the adventure of riding "rough waves" (Santini/Mehler/Sharoff 2011: 9). Indeed, the WWW poses significant problems to genre research. Santini/Mehler/Sharoff (2011: 9), for instance, voice their impression that webbased documents are "much more uncontrolled and unpredictable" as compared to printbased/“old media' genres. Similarly, Giltrow/Stein (2009a: 9) also refer to the "chameleon-like properties of Internet genres". Therefore, recent research on web-based genres frequently dwells on a central paradox: Genres are recurrent forms of communicative action. But grasping the recurrent (assuming that it exists) in a WWW which is in "a permanent state of transition" (Crystal 2006: 16) appears to be highly challenging.

However, studies in Giltrow/Stein (2009b) stress the stability of web-based genres and some even accentuate transmedial continuities, for instance with regard to online diaries (McNeill 2009) and genres of digital folklore (Heyd 2009). These studies illustrate the potentials of a shift in perspective from synchronic to diachronic genre research in order to perceive the stability of recurrence under the fluid surface of the WWW's "rough waves".

The aim of this article is twofold: (1) I will argue for a diachronic approach to web-based genres as one way of meeting the challenges of a linguistic description of web-based genres. (2) The

\footnotetext{
* I am particularly indebted to my colleague Jana Pflaeging for lending my thoughts a visual form and Alexander Brock for his invaluable advice. Additionally, I would like to thank the anonymous reviewers for their helpful remarks on earlier versions of this paper.
}

Linguistik online 80, 1/17 - http://dx.doi.org/10.13092/lo.80.3567

CC by 3.0 
potentials of this approach are explored using the example of the personal weblog, which looks back on a history of more than 15 years.

I will first situate my paper in the context of genre and (diachronic) blog-research and define what is called a "diachronic approach" here. This will lead to the research questions, followed by an outline of the research corpus and methodology. The results section will first focus on recurring features of the personal weblog and then present a model of its development based on corpus data and historical sources. I will conclude this paper by referring back to my research questions and formulating objectives for future genre research.

\section{Background}

\subsection{Genre and Communication Form}

Genres such as the personal weblog are seen here as categories of everyday life which group texts exhibiting similar, recurring characteristics. Figure 1 below illustrates this by including a layer of textual realisations, which is linked to a more abstract layer of genre as grouping of these texts. Genres can be described on several inter-related dimensions (cf., e. g., Devitt 2009). Here (see the genre layer in Figure 1), I will differentiate the descriptive levels of situation, function and structure (linguistic and multimodal).

As the grouping of texts is always a cognitive process which draws on specific knowledge that is shared (to some extent) in a community, genres are also cognitive devices, "useful for author and reader alike in forming the understanding of a text" (Karlgren 2011: 33), and show prototypical structure (cf., e. g., Brock 2013; Sandig 2000). Figure 1 captures this aspect, too: Members with a higher degree of family resemblance are situated close to the centre of the category, whereas others are located at several points between the centre and periphery. This cognitive aspect of genres, i. e. the underlying knowledge that allows users to recognise, classify and produce texts of a certain genre, can be reconstructed from actual occurrences.

Following Lemke (1999), Figure 1 also depicts a clustering of several exemplars around the prototype, as a general orientation towards the prototype can be assumed. As "instrumental categories" (Karlgren 2011: 33), genres usually acquire a common label within their community (cf. Miller 1984: 155).

The base level in Figure 1 illustrates the communication form layer, which is also an integral part of genre description (cf. Askehave/Nielsen 2005: 125). The term communication form originated in German media linguistics and has gained various readings (cf. Brock/Schildhauer forthc.). Here, it is used here to denote technical constellations which give rise to certain affordances (cf. Hutchby 2001). These potentials and constraints, in turn, can be used to produce texts of various genres. Usually, genres differ with regard to what specific potentials of a certain communication form are typically used (or not). Adopting Thaler's (2007) view on media, ${ }^{1} \mathrm{I}$ assume the following layers of the communication form to be relevant for the WWW:

\footnotetext{
1 The term medium itself is highly polysemous (see, e. g., Dürscheid 2005). In order not to get trapped in several readings of the term and because of the wide acceptance of the term communication form in German media linguistics at least, I will refrain from talking about media and use communication form instead.
} 


\begin{tabular}{|c|c|}
\hline $1^{\text {st }}$ Layer & $\begin{array}{l}\text { - the infrastructure of the Internet, including protocols such as TCP/IP and } \\
\text { standards like, for instance, HTML }{ }^{2}\end{array}$ \\
\hline $2^{\text {nd }}$ Layer & $\begin{array}{l}\text { - } \text { software }^{3} \text { building on the infrastructure, for instance blog-software such as } \\
\text { Blogger or WordPress as well as } \\
\text { - the specific implementation of this software: WordPress.com and } \\
\text { WordPress.org are different implementations of essentially the same } \\
\text { software package, with considerable consequences for usability and } \\
\text { potentials. }{ }^{4}\end{array}$ \\
\hline
\end{tabular}

Table 1: Layers of the Communication Form Relevant to Blog Genres

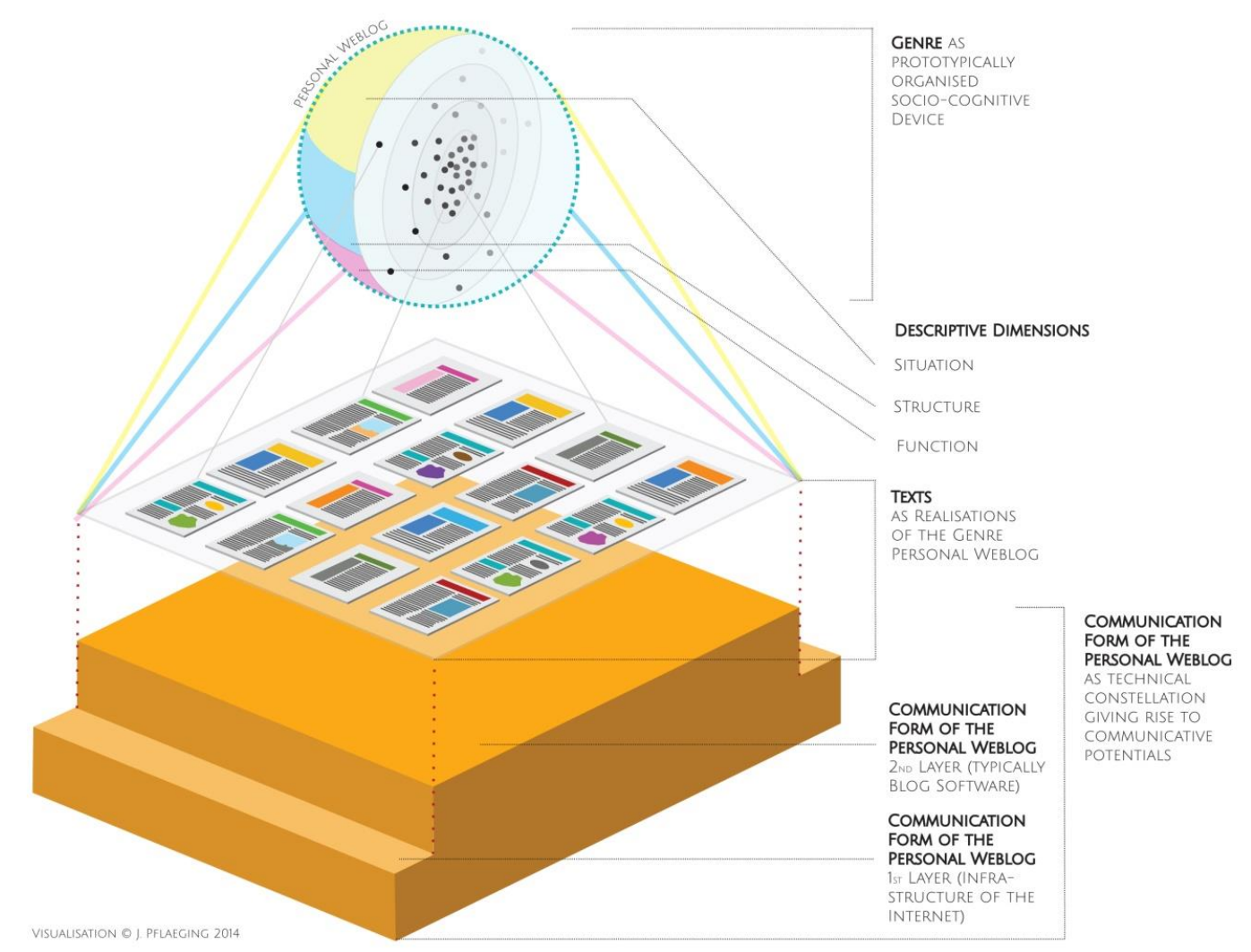

Figure 1: A Genre Model of the Personal Weblog (visualised by J. Pflaeging)

\subsection{Genre Profiles}

Luginbühl (2014: 312-313) shows that genres exist on different levels of complexity. For instance, the super-genre TV news show constitutes a constellation of several genres (e. g.,

\footnotetext{
2 One reviewer suggested differentiating between physical infrastructure and technical standards on this first layer of the communication form. While I agree that this differentiation could be made in principle, it would not benefit the analysis conducted here. See, e. g., Galloway/Thacker (2004) for a very fine-grained differentiation of the technical standards subsumed under the first communication form layer here.

${ }^{3}$ One reviewer suggested a further differentiation into software vs. platforms. As platform apparently refers to what I call blog system here and is, essentially, a software-implementation as well, I refrain from making this distinction here.

${ }^{4}$ Thaler (2007: 156-157) exemplifies this by referring to different implementations of chat technology, e. g. by granting specific operator-rights to individual participants in a specific chat environment.
} 
interview, lead-in, package etc.), which are more delimitated in terms of structural characteristics than the super-genre they are part of (Luginbühl 2014: 316-317). Luginbühl's concept genre profile is concerned "with the contour of genres within a super-genre like a TV news show" (2014: 313) and enables describing super-genres in terms of the repertoire, frequencies and intertextual relations of the more delimitated genres they encompass. I will assume that the personal weblog, in fact, constitutes such a super-genre - a constellation of several genres of postings. ${ }^{5}$

\subsection{Genre Change}

Genre change can be modelled mainly as caused by a reproductive cycle: If innovations in specific texts are repeatedly reproduced by genre users, the prototypical core of the category begins to shift (cf, e. g., Bateman 2011: 248). Recently, research has identified a variety of genre change patterns (cf., e. g., Bolter/Grusin 2001; Brock 2009; Luginbühl 2014; Stöckl 2010). The current study draws on the following: 6

- Evolutionary Change. Stöckl (2010:145) uses this term to describe a genre's gradual change regarding one specific feature. As some users may reproduce established patterns rather than instantly follow the change, the process usually involves a temporary widening of the genre category. This will, for instance, become apparent in the discussion of the use of images in personal weblogs below (Table ).

- Genre Split. During a genre split, a new genre develops out of an established genre. A group of texts gradually shows different features with respect to at least one dimension according to the mechanism of evolutionary change just outlined. After a phase of overlap, both genre categories are perceived as distinct, with separate labels assigned to them. It can be imagined, for instance, that vlogs split off as a distinct blog genre when video clips were used increasingly by some authors until a new way of blogging was perceived and labelled as such.

- Pattern Embedding. Patterns are salient and clearly delimited aspects of a genre which can occur on all layers of the genre model. Pattern embedding describes the import of a pattern from one genre to another one, which is usually perceived as such by recipients, for instance when blog postings are written in form of a poem. Pattern embeddings can occur in one or a few texts only or they can become firmly established and thereby part of the receiving genre.

- Migration. Migration describes the process of transferring a genre from one communication form to another. ${ }^{7}$ This transfer involves the application of established genre knowledge to a new medial context. The resulting cognitive link between genre ancestor and the migrated genre can be reconstructed from genre users' explicit reference to genre ancestry - as is, for instance, visible in the genre label online diary.

\footnotetext{
${ }^{5}$ In this paper, I will focus on selected aspects of repertoire and frequency and leave intertextual relations for future research.

${ }^{6}$ The conceptualisation of these patterns is also indebted to Lemke's (1999) idea of locating genres in a topological space.

${ }^{7}$ This process has been mentioned at least in passing by various researchers, e. g. Askehave/Nielsen (2005: 124125), Giltrow/Stein (2009a: 9) and Heyd (2009: 246).
}

ISSN 1615-3014 


\section{$2.4 \quad$ Blogs}

Scholars mainly agree that blogging is a phenomenon which goes back (at least) to the end of the 1990s, when Jorn Barger coined the term weblog. With its "concentration on blogging" (Giltrow/Stein 2009a: 14), Giltrow/Stein's (2009b) volume is indicative of an abundance of research which has dealt with blogging since then. In the succession of Herring et al.'s seminal studies (Herring et al. 2004, 2005, 2006), blogging has been investigated from a number of different perspectives (see Puschmann 2013 for an overview). While many of the early studies address blogging in general, later works have described several blog genres, for instance the corporate blog (Puschmann 2010) and the personal weblog (Lomborg 2009, 2014). Recently, research and academic blogs (see, e. g., Efimova 2009; Mauranen 2013) have increasingly gained attention.

A diachronic perspective, especially regarding the origins of blogging in online and offline contexts, is taken by Miller/Shepherd (2004; 2009), who propose phases of the history of the personal blog. The authors follow an "interpretive-rhetorical approach" (Miller/Shepherd 2004) and rely mainly on bloggers' own impressions. Blogger Rebecca Blood (2000; 2002), especially, has been referred to by Miller/Shepherd and others (e. g., Herring et al. 2004; Hoffmann 2012). Blood's (2002: 6-9) blog categories blog, filter and notebook have, however, been deemed by Puschmann (2013:90) as "somewhat prescriptive". Claims on blogging history based mainly on bloggers' accounts therefore have to be complemented by further text analysis. Particularly the development of the personal weblog as "the best known, perhaps the prototypical representative of the species in public awareness" (Mauranen 2013: 7) has not yet been traced on the basis of a diachronic corpus. The personal weblog therefore lends itself to testing the benefits and limitations of a diachronic approach to web-based genres.

\subsection{A Diachronic Approach}

According to Ferdinand de Saussure, the term diachronic denotes an analytical perspective on language which takes the temporal dimension into account. De Saussure states that a diachronic analysis will always discover instances of change as "l'immobilité absolue n'existe pas" (Wunderli 2013: 226). This is certainly also true for genres: "Genres come from somewhere and are transforming into something else" (Schryer 1993: 208). However, features on different layers of a genre may change at a different pace. Therefore, both continuity and change may be observed in one and the same genre at a time. The necessity of continuity in genres follows from their function as cognitive devices outlined above.

As a diachronic approach to genre has to reconstruct past contexts of language use (cf. Giltrow 2013: 724), it necessarily has to make use of historical sources. However, the discussion so far has shown that this should be complemented by textual analysis. Therefore, a diachronic approach, as it is understood here, does not only include a time-sensitive perspective. It incorporates both the analysis of historical sources and artefacts of the genre in question. 


\section{$3 \quad$ Study Design}

\subsection{Research Questions}

These deliberations lead to the following general research question:

What are the possible benefits and limitations of a diachronic approach to web-based genres as defined here?

Possible answers to this question are explored using the example of the personal weblog. Concerning this genre, the paper pursues the following questions:

1. What genre features of the personal weblog can be considered recurrent and stable, and what features have changed over time?

2. How does the personal weblog relate to other genres in both online and offline contexts, particularly concerning the weblog and the diary?

3. What phases of development of the personal weblog can be proposed on the grounds of both corpus data and historical documents and how do these relate to other models proposed so far?

\subsection{Basic Analytical Units: Blog-Page and Posting}

Before describing the research corpus of this study, the two analytical units need to be clarified which both the corpus setup and analysis are based on.

Blog-Page: This term refers to the homepage of a blog, which can be reached by entering the blog's URL into the browser's address bar. It comprises the content that can be viewed by horizontal and/or vertical scrolling, without clicking on hyperlinks or entering a new URL.

Posting: Typically, the main part of a blog-page displays several postings. Postings on blogs that use a software (e. g. Blogger) can be defined as content-unit that is published at once by clicking the publish button (or similar). Formally, a posting is usually delimited by a headline (top) and a timestamp (bottom). ${ }^{8}$

\subsection{Corpus}

The present study is based on the diachronic blog corpus DIABLOC, which was compiled manually in 2012-2013 by use of the Internet Archive. ${ }^{9}$ The corpus contains blog-pages (see above). For each blog-page, the DIABLOC comprises a link to the original page on the Archive, a text file of the postings, and a pdf file for multimodal analysis. For every blog-page, I used the earliest version available that was archived with sufficient quality. ${ }^{10}$

For corpus compilation, I relied on an ethno-category based approach: If members of the community assign a certain genre label to a text, it can be counted as corpus candidate.

\footnotetext{
${ }^{8}$ Determining postings is less straightforward for the weblogs of the mid-to-late $1990 \mathrm{~s}$, which do not make use of blog-software. However, postings are often nevertheless accompanied by timestamps even on those early weblogs so that I resorted to defining postings as content-units between two timestamps in these cases.

${ }^{9}$ www.archive.org - the Internet Archive contains snapshots of webpages dating as far back as 1996.

${ }^{10}$ As the FAQ-page of the Archive states, not every snapshot is of equal quality. Sometimes, for instance, layout information is missing or images are not archived (http://archive.org/about/faqs.php\#The_Wayback_Machine).
} 
Following the discourse of the blogging community, I used the following genre labels for the current study: 11

- Weblog. This is the first blogging-related genre label, coined by Jorn Barger in 1997. The term is applied by two other weblog-authors - Jessie James Garret (Infoshift) and Cameron Barrett (Camworld) - to all websites resembling theirs in 1998 and 1999. Thereby, it became a genre label for first generation blogs - the practice of a fairly small community. Part I of the research corpus (Table 2 below) contains 30 of these weblogs. In order to compile these texts, I used Garret's listing of ye olde school-weblogs ${ }^{12}$ as well as Cameron Barrett's blog roll on his weblog Camworld from 199913, which the author used to collect "other sites like his" (Blood 2000). These sources were triangulated with Blood (2000) and several others (e. g., Barrett 2009a/b; Winer 2001 and Rosenberg 2009) and together provide a useful gateway to the weblogs of the first generation community. These weblogs have been included in this study in order to allow for the closest possible analysis of the origins of the personal weblog. ${ }^{14}$

- Personal weblog. After its occasional use by first generation bloggers, the first blog directory Globe of Blogs (founded in 2002) uses this term. It occurs as a meta-category (i. e., not bound to a particular topic) in the category system which authors can use to classify their blog on Globe of Blogs. As the categories apparently are created by the users of this directory, its occurrence here is a strong indicator that the personal weblog has been used as a genre label within the blogging community since 2002 the latest. In order to compile part II of the research corpus (Table 2 below), I entered the list pages of the personal weblog-category of Globe of Blogs via the Internet Archive. ${ }^{15}$

\footnotetext{
11 The term blog itself is used as a hyperonym for a number of blog-genres such as the corporate blog, the science blog and others and was therefore not relevant for the corpus compilation.

12 http://web.archive.org/web/20000118102938/http:/jjg.net/portal/tpoowl.html.

13 http://web.archive.org/web/19990202092137/http:/www.camworld.com/.

14 One reviewer assumed that the weblog genre split into a number of different genres, with the personal weblog being only one of them. However, the sources suggest rather that the personal weblog provides an intermediate stage between the weblog and further blog genres such as the employee blog, the corporate blog and the science blog. These have not been sampled and analysed here; however, there are comprehensive studies of each of these, which I relied on for comparison whenever necessary.

15 Considering this ethical dimension of corpus compilation, I followed the guidelines set by the Association for Internet Research (Ess/AoIR ethics working committee 2002). As the blog-pages are publicly available and even registered in a directory, using the blogs' titles and hyperlinks can be considered a minor ethical risk.
} 


\begin{tabular}{|c|c|c|c|c|c|c|}
\hline & & & & $\begin{array}{l}\text { Blog- } \\
\text { Pages }\end{array}$ & Postings ${ }^{16}$ & Word Forms ${ }^{17}$ \\
\hline \multirow{5}{*}{ 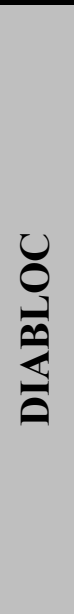 } & $\begin{array}{l}\text { Period I } \\
\text { Weblogs }\end{array}$ & & $1997-2000$ & 30 & 775 & ca. 34,075 \\
\hline & \multirow{4}{*}{$\begin{array}{l}\text { Period II } \\
\text { Personal } \\
\text { Weblogs }\end{array}$} & II.A & $2002-2005$ & 100 & 1091 & ca. 224,025 \\
\hline & & II.B & 2006-2008 & 100 & 786 & ca. 211,420 \\
\hline & & II.C & 2009-2012 & 100 & 901 & ca. 302,017 \\
\hline & & & Total: & 330 & 3,553 & ca. 771,537 \\
\hline
\end{tabular}

Table 2: The Diachronic Blog Corpus

As Globe of Blogs was only launched in 2002, the year 2001 could not be covered. The corpus was complemented by historical sources, such as essays written by blog-authors on genre issues (e. g. Barrett 1999a/b, Blood 2000) and blogging manuals, which were used to reconstruct the respective communication forms (see the list at the end of this article).

\subsection{Methodology}

This study made use of a mixed-methods approach and thus combined qualitative with quantitative steps. The framework was inspired by Grounded Theory (Glaser/Holton 2004). As illustrated by Figure 2, analytical categories were generated from three different kinds of sources: previous studies (esp. of ethnographic nature, e. g. Nardi/Schiano/Gumbrecht 2004; Nardi et al. 2004), historical sources and corpus material. Most qualitative results were quantified (descriptive statistics) in order to allow for plausible assumptions on the continuity or change of a certain feature (see, e. g. authorship, identity indicators and posting genres below). The framework is circular as the discovery of new insights or sources will provide new input to category formation and qualification. ${ }^{18}$

Figure 2 shows in particular how this framework was applied to the analysis of posting genres, which triangulated insights from previous studies and the meta discourse of the blogging community (step I), explicit comments on the genre of a certain posting (e. g. labelling a posting as review, step II), and from linguistic analysis (e. g. topic, pronouns, deictic elements, cohesive devices, use of hyperlinks etc., steps II and III). Figure 2 depicts step III as circular in itself because individual cases were constantly compared until saturation was reached.

\footnotetext{
16 On average, one blog-page contains 28.8 postings in period I, 10.9 in II.A, 7.86 in II.B and 9.18 in II.C.

17 This is only a rough estimate as no sophisticated tokenizer (word processor) was used.

18 Interviews and introspective statements used in this study were, e. g., taken from Rosenberg (2009) and Benton (2006 a/b), but also from studies such as Nardi et al. (2004).
} 


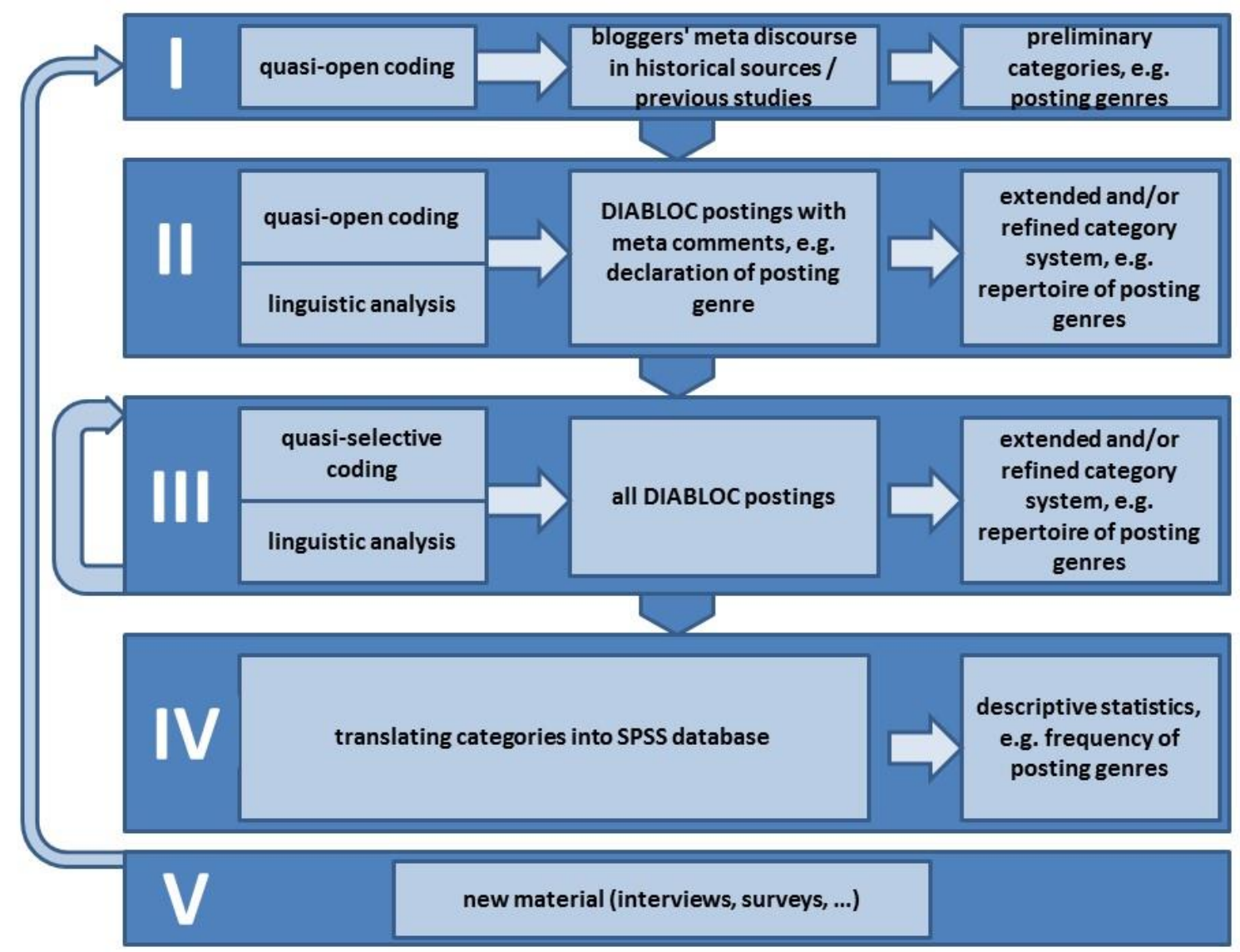

Figure 2: Methodology for Posting Genres

The analysis of the textual surface of corpus texts was complemented by mining the HTMLsource code, providing, among others, information on the use of blog-software. WordSmith was used for lexical corpus analysis. MaxQDA 10 served as tool for the qualitative steps.

\section{$4 \quad$ Recurring Features of the Personal Weblog}

In this section, I will focus on selected recurrent aspects of the personal weblog and show how these can be traced back to the weblog as their immediate ancestor. The following section will present a stage model of the development of the personal weblog genre.

\subsection{Single Authorship}

Weblogs and personal weblogs are typically kept by one author only (Diagram 1). This is remarkable as the communication forms of both period I (hand-coded HTML-sites) and II.C (sophisticated blog-software offering options for inviting multiple authors) provide the potential of multiple authorship. 


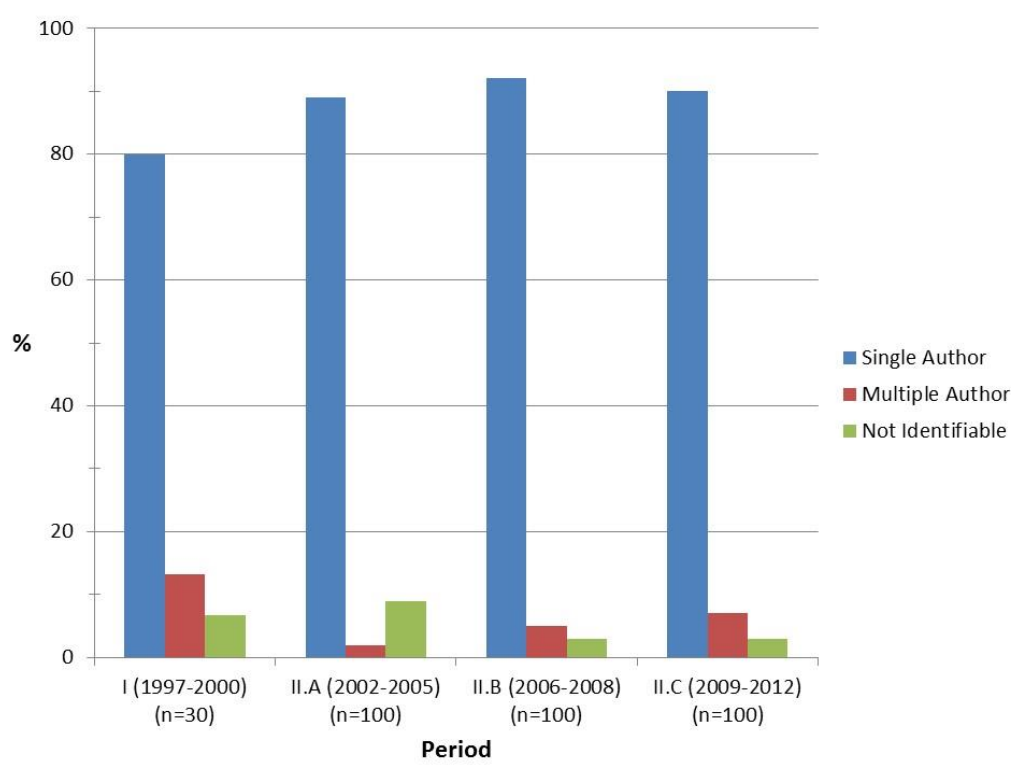

Diagram 1: Single- and Multiple Authorship (n: number of blog-pages)

\subsection{Immediacy}

Typically, blogging is bound to the author's current situation, following an "ethos of immediacy" (Reed 2005: 227). This becomes particularly evident in the use of proximal deictic expressions, for instance the adverbs here and now as well as the present progressive in the following examples:

(1) And now? Now all soapy and mellow from the bath what I really fancy is a glass of merlot. But I'm not going to do that. I'm going to go to bed.

(All back to mine 26, period II.A)

(2) So here I am, on Christmas night. My family is asleep, and I'm laying on my stomach listening to Sarah McLachlan

(Alone in Tacoma 50, period II.B)

The deictic centre for the interpretation of these expressions is provided by the entry's timestamp (cf. Puschmann 2013: 91). 


\begin{tabular}{|c|c|c|c|c|c|c|c|c|c|}
\hline & \multirow[t]{2}{*}{$\begin{array}{l}\text { Freq. } \\
\text { BNC }\end{array}$} & \multicolumn{2}{|c|}{$\begin{array}{c}\text { Period I } \\
(1997-2000)\end{array}$} & \multicolumn{2}{|c|}{$\begin{array}{l}\text { Period II.A } \\
(2002-2005)\end{array}$} & \multicolumn{2}{|c|}{$\begin{array}{l}\text { Period II.B } \\
(2006-2008)\end{array}$} & \multicolumn{2}{|c|}{$\begin{array}{l}\text { Period II.C } \\
(2009-2012)\end{array}$} \\
\hline & & Freq. & LLH & $\begin{array}{l}\text { Fre } \\
\text { q. }\end{array}$ & LLH & $\begin{array}{l}\text { Fre } \\
\text { q. }\end{array}$ & LLH & Freq. & LLH \\
\hline I & 7.4 & 12.6 & 69.87 & 26.3 & $\begin{array}{r}2560.0 \\
1\end{array}$ & 27.4 & $\begin{array}{r}2899.0 \\
2\end{array}$ & 26.6 & $\begin{array}{r}2839 . \\
78\end{array}$ \\
\hline WE & 3.0 & - & - & - & - & 4.1 & 28.50 & 4.2 & 38.61 \\
\hline HERE & 0.7 & - & - & 1.2 & 28.26 & 1.8 & 110.07 & 1.8 & $\begin{array}{r}123.6 \\
9\end{array}$ \\
\hline NOW & 1.4 & 2.1 & $7.8^{\mathrm{a}}$ & 2.2 & 37.29 & 2.0 & 19.21 & 1.9 & 13.86 \\
\hline TODAY & 0.2 & 0.5 & $6.27^{\mathrm{a}}$ & 0.9 & 101.14 & 0.7 & 53.13 & 0.6 & 31.76 \\
\hline $\begin{array}{l}\text { YESTER } \\
\text {-DAY }\end{array}$ & 0.2 & - & - & 0.3 & 9.90 & - & - & - & - \\
\hline
\end{tabular}

Table 3: WordSmith Match of Frequency Counts per 1000 words - DIABLOC vs. BNC (a: $p=0.01$, otherwise p $<0.0001$; LLH $=$ Log Likelihood, cf. Dunning 1993) ${ }^{19}$

Table 3 lists proximal deictic elements of person $(I$, we), place (here) and time (now, today) and compares their frequencies in the BNC (British National Corpus, 100 Mio tokens) with the respective DIABLOC periods. The table was calculated using a WordSmith word list match, which gives only items that are used significantly more often or less often than in the reference corpus (here: the BNC). It becomes apparent that the frequency of proximal deictic expressions is indeed significantly higher in personal weblogs than in the reference corpus. This holds, to a limited extent, also for weblogs in period I. Yesterday is no proximal deictic element as it points away from the deictic centre. It was, however, included under the assumption that blog authors would use it frequently to tell about the immediate past. Interestingly enough, it is only listed in period II.A. This supports the assumption of an "ethos of immediacy": Bloggers apparently rather tell what has happened today.

\subsection{Authenticity and Choice of Names}

Bloggers have been claimed to stage a close link between their offline and their blog identity (see, e. g., Karlsson 2006), thereby giving the impression of authentic self-disclosure. ${ }^{20}$ An important role in this respect has been assigned to the bloggers' choice of online names, which usually appear as a signature in the timestamp (see, e. g., Viégas 2005). Herring et al. (2006: 5) summon the variable "choice of name" under the label "identity indicator", apparently assuming that a full name is a stronger indication of offline identity than, say, a pseudonym.

\footnotetext{
${ }^{19}$ Not all DIABLOC texts are British so that, strictly speaking, the BNC has only limited validity as a reference corpus. However, frequency counts per 1000 words obtained from the Corpus of Contemporary American English (http://corpus.byu.edu/coca/) yield results which are very similar to the BNC. The table presented here can therefore serve to illustrate the exceptional frequency of proximal deictic elements in (personal) weblogs.

${ }^{20} \mathrm{Cf}$. Baumer/Sueyoshi/Tomlison (2008: 1116).
} 
In period I (Diagram 2), it seems to be conventional for bloggers to provide their full names. This observation does not hold for the entire period II, even though a tendency towards the full name-convention towards II.C can be observed. In general, period II-bloggers tend to give some higher identity indicator, i. e. first, last or full name. Pseudonyms such as Linky (I) and linearchild (II.C) are used decreasingly after a temporary rise in II.A.

A name on a blog-page can usually not be proven to be identical with the author's real name. However, the choice to display a full name creates the impression on the recipients' side of increased knowledge about the author's identity, which can be argued for on the grounds of the Gricean quality maxim (cf. Grice 1975) and a "presumption of honesty" even in online environments (Yus 2011: 41). Karlsson (2006: 9) reports that in her "survey [of weblog readers, P.S.], a mere $5 \%$ of the respondents had ever distrusted the truthfulness of the identity presented in the weblog." On this basis, authentic self-presentation (or evoking the impression thereof) can be concluded to be both an expected and a recurrent feature of personal weblogs.

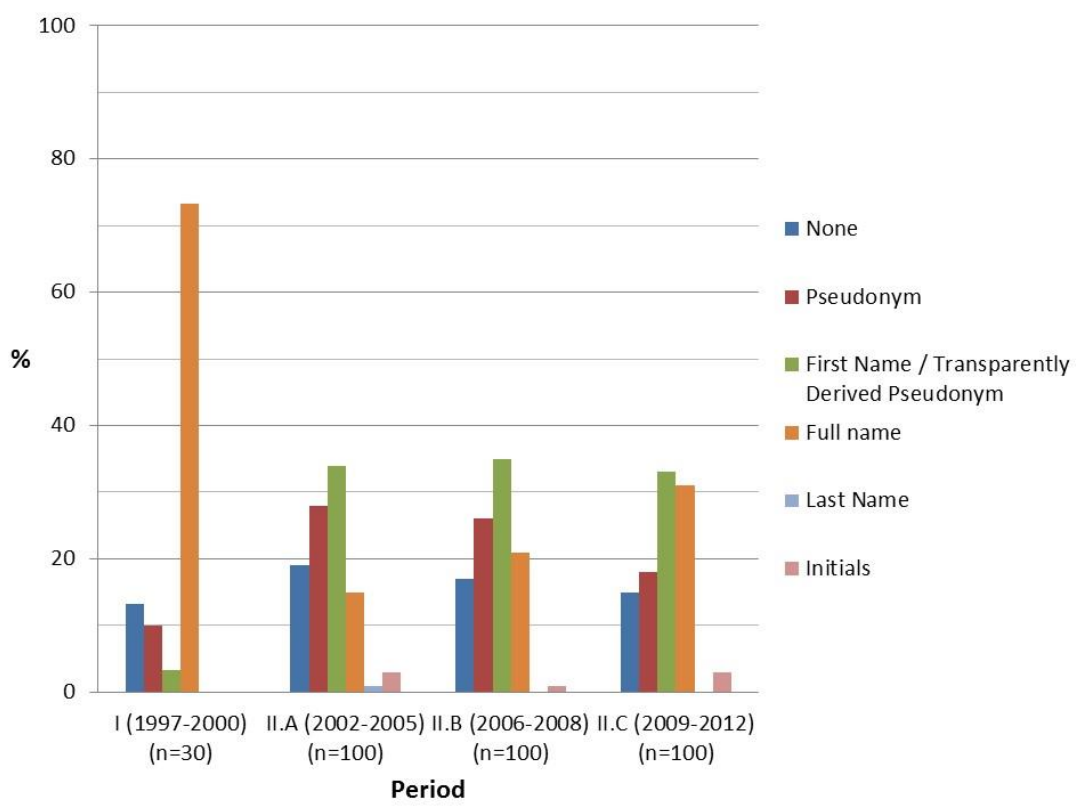

Diagram 2: Choice of Names (n: blog-pages)

\subsection{Posting Genres}

The repertoire of posting genres of the personal weblog as a super-genre (see above) was determined by the procedure outlined in Figure 2. Usually, only a selection of these posting genres occur on a specific blog-page - on average, between two and three. 


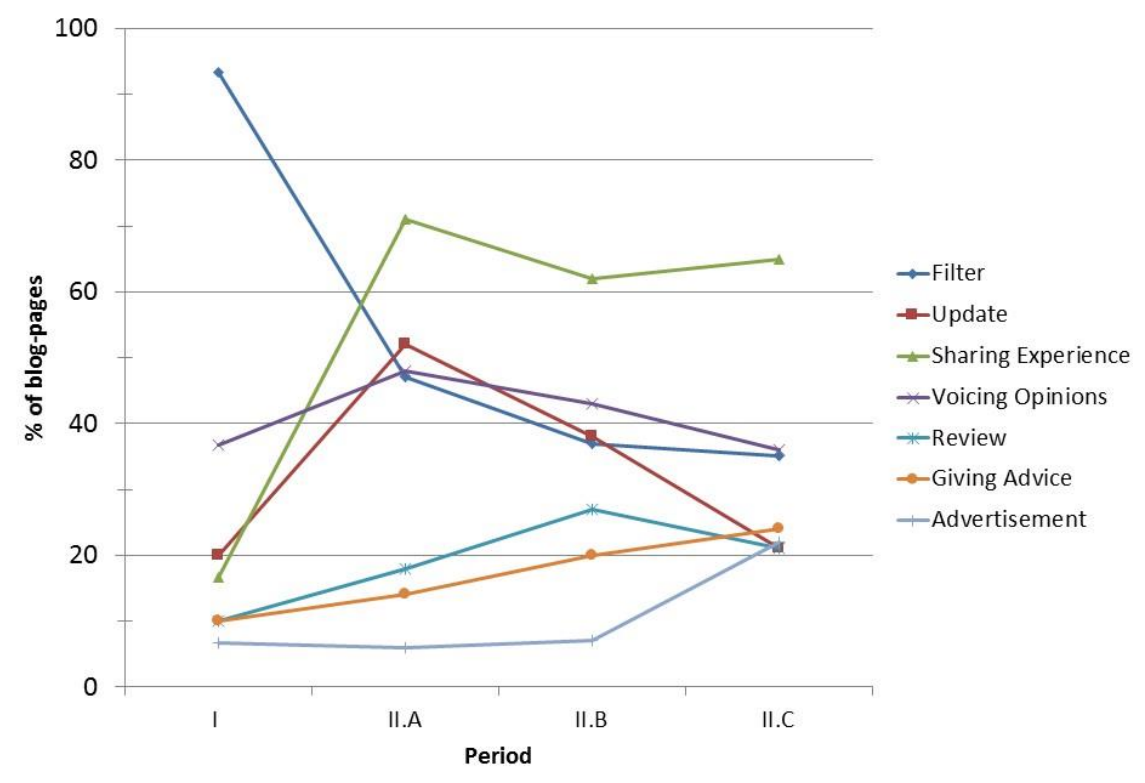

I (1997-2000) $n=30$ | II.A (2002-2005), II.B (2006-2008), II.C (2009-2012) $n=100$

Diagram 3: Repertoire and Frequency of Posting Genres (n: blog-pages)

Diagram 3 shows the percentage of blog-pages per period on which selected posting genres could be detected. ${ }^{21}$ The genre repertoire remains constant from period I onwards, which both allows the claim of recurrence in this respect and underlines the continuity between the personal weblog and its ancestor, the weblog of period I. What is most notable in Diagram 3 is the shift from filter- to sharing experience-postings as core posting genres from I to II.A. This observation leads to the next point, in which I will turn to issues of genre change and provide descriptions of these central posting genres. ${ }^{22}$

\section{$5 \quad$ Phases of the History of the Personal Weblog}

\subsection{Emergence and Consolidation of the Weblog (1997-1999)}

\subsubsection{Filter-postings}

Filter-postings are so prototypical of period I that first generation authors define the genre weblog with reference to this posting type:

(3) Weblogs are often-updated sites that point to articles elsewhere on the web, often with comments, and to on-site articles. A weblog is kind of a continual tour, with a human guide who you get to know.

(Winer 2001)

The following example (4) provides an excerpt of Winer's own weblog:

\footnotetext{
${ }^{21}$ I counted one occurrence per blog-page as an instance of a posting genre being detectable. As, usually, up to 3 different genres could be detected on one blog-page, the percentages do not add up to $100 \%$.

${ }^{22}$ Due to restrictions of space, I cannot go into detail on other posting genres here. See Schildhauer (2016: 200-239) for details on other posting genres.
} 
(4) New Frontier sites: Calvary Presbyterian Church, Barreau du Québec, The Pixel Pen.

It seems like I'm pointing to HotWired's Packet channel every day. Today's piece by Simson Garfinkel is an invaluble explanation of how MAE West works. Our ISP, Conxion, is linked into MAE West, which means that DaveNet and Scripting News come thru the MAE system (I think...).

ZipIt is a Macintosh program that zips and unzips archives in a format fully compatible with PKZip for the IBM and zip implementations on other systems. It's vastly easier to use than the Windows equivalent program, WinZip, which is a dauntingly complex maze of wizards and vacuous help files.

(Scripting News 31-34, period I)

Example (4) shows that filter postings often appear in the form of lists of topically-unconnected items (new frontier sites, MAE West, ZipIt). The commentary on the hyperlinks tends to be short and concise - (4) contains a number of acronyms such as MAE, ISP and others - and also serves to reveal the author's expertise in a certain (mostly IT-related) field (cf. Blood 2002: 63). The tendency to conciseness is also mirrored in strategies of embedding hyperlinks in a witty manner, for instance creating coherence gaps that lead readers to actually follow the links:

(5) Could this be why WebTV (ahem, Microsoft) dropped support for Java?

(Camworld 11, period I)

\subsubsection{Number of Hyperlinks}

The importance of filter-postings in period I (and their decline in later periods) is mirrored by the frequency of hyperlinks pointing to external sources (see also Myers 2010: 30) for similar values on blog-hyperlinks in general), which declines significantly from period I to period II.A:

\begin{tabular}{ccccc}
\hline Period & Min & \multicolumn{1}{l}{ Max } & Mean & \multicolumn{1}{l}{ SD } \\
\hline I (1997-2000) & 0.00 & 179.00 & 41.14 & 39.43 \\
II.A (2002-2005) & 0.00 & 47.94 & 4.33 & 6.38 \\
II.B (2006-2008) & 0.00 & 65.07 & 5.19 & 9.59 \\
II.C (2009-2012) & 0.00 & 54.77 & 4.37 & 7.46 \\
\hline
\end{tabular}

Table 4: Frequency of External Hyperlinks per Blog-Page per 1000 Words

In sum, the implementation of external hyperlinks can be seen as typical of period I and far less important for later periods. Interestingly, the standard deviation is much higher for period I than for period II: While some first generation weblogs provide impressive lists of links (e. g. Perfect), PigDog, for instance, does not feature external hyperlinks on its homepage at all.

\subsubsection{Dating the Emergence of the Weblog}

The weblog Scripting News quoted in (4) is launched in January 1997 (see Winer 2001). Its author Dave Winer is a leading figure of the mid-1990s IT-scene, with his mailing list DaveNet 
(founded in 1994) and the 24 Hours of Democracy Project (1996) contributing to his increasing influence (cf. Rosenberg 2009: 59). Scripting News therefore easily grows into both a model and a catalyst for the emerging genre, with Jorn Barger and other bloggers-to-be following his example. ${ }^{23}$ The launch of Scripting News can therefore count as the beginning of the emergence of the weblog.

\subsubsection{The Emergence of the Weblog in the Context of Other Genres}

Figure 3 below, which integrates essential elements of the genre model outlined in Figure 1, illustrates the emergence of the weblog out of a network of established genres.

A migration process (see the bold arrow in Figure 3) can be assumed for the offline genre logbook: The genre label weblog is an instance of the metaphor USING THE WWW IS A (SHIP)VOYAGE, which is also mirrored in compounds such as webtravel or the browser name Netscape Navigator. With its "nautical air, a Star Trek echo" (Rosenberg 2009: 79) the compound $w e b+\log (b o o k)$ neatly fits this conceptual realm. Thereby, the genre label makes explicit reference to the logbook as its offline ancestor; a typical posting in period I logs the author's webtravels.

An important genre split involves the personal homepage as an online ancestor of the weblog (thinly dotted arrow in Figure 3), which also serves purposes of self-presentation on the WWW (cf. Rosenberg 2009: 24-28; see also Chandler 1998). Period I bloggers search for possibilities of overcoming the static presentation of contents on personal homepages. The majority (80\%) switch to the post-paradigm (cf. Bausch/Heughey/Hourihan 2002: 88), presenting all postings on one page in reverse chronological order. Others $(20 \%)$ adhere to the page-paradigm: Need to Know as well as Linky \& Dinky, for instance, publish one page per week. Both solutions allow for the presentation of new contents without losing readability or deleting older information. Regarding both the dynamics of contents and its presentation, the weblog diverges from the personal homepage, which continues to exist.

Pattern embedding also seems to have contributed to the emergence of the weblog (densely dotted arrows in Figure 3): When Need to Know and Linky \& Dinky publish one page per week with several topical sections, they implement e-zine patterns of publication. The newspage, rooted in Tim Berners-Lee's What's New-site, is a likely source for the pattern of the reverse chronological order (cf. Rosenberg 2009: 59).

\footnotetext{
${ }^{23}$ Winer (2001) offers his 24 Hours of Democracy-site as the first Weblog. However, this site has never been labelled weblog by anyone else and did not exert the role model influence of its successor Scripting News.
} 


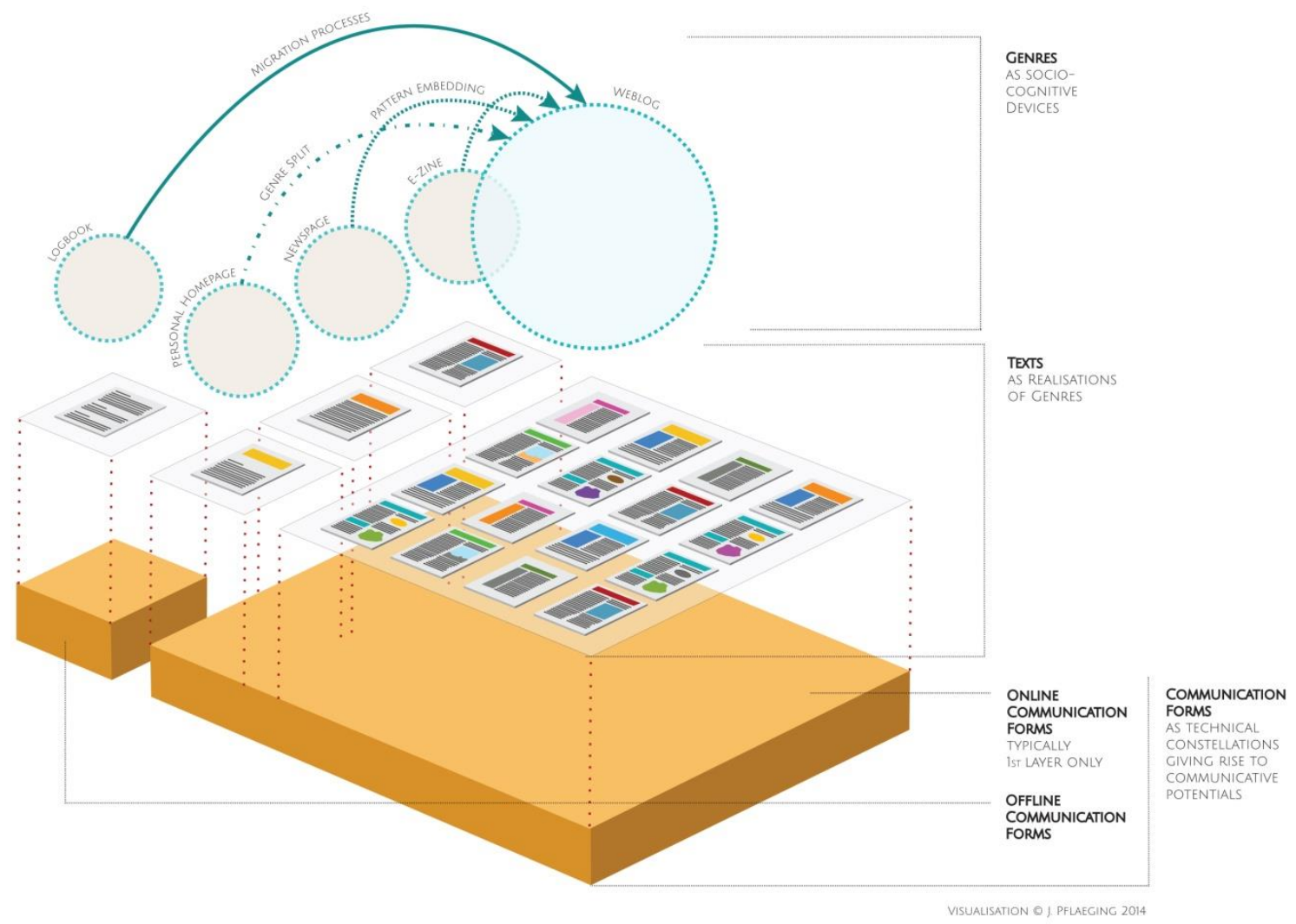

Figure 3: Emergence of the Weblog in the Context of other Genres (visualised by J. Pflaeging)

\subsection{The Crisis of the Weblog and the Emergence of the Personal Weblog (1999-} 2000/2001)

\subsubsection{Growing Fuzziness of the Weblog-Genre}

At the beginning of 1999, more and more weblogs are created. As early as in the first months of 1999, Brigitte Eaton, who wants to compile a catalogue of all weblogs, ${ }^{24}$ withdraws to the single criterion "that the site consist of dated entries" (Blood 2000). Debates about what can be considered a weblog spread, as illustrated by Cameron Barrett's essays (Barrett 1999a/b). In terms of genre description, the category weblog increasingly contains peripheral members. Consequently, the fuzziness of the category boundaries intensifies.

\subsubsection{The Role of Blog-Software}

After the launch of Blogger in August 1999, the use of blog-software increases rapidly (Diagram 4). A specific blog communication form develops, as the software is explicitly designed by bloggers to cater for the needs of blog-authors. 25 The user-friendliness of these new blog-systems can be assumed to attract wider circles of potential blog authors not familiar with HTML-coding. Because the weblog genre grows increasingly fuzzy at the beginning of

\footnotetext{
24 Eaton's blog portal apparently cannot be accessed via the Internet Archive.

25 Cf. Rosenberg (2009: 108-111).
} 
1999, half a year before Blogger's launch, it appears plausible to view the spread of blogsoftware as a catalyst of a process already under way rather than its cause. This view is supported by the fact that it is only in period II.B that the use of blog-software can be proven for nearly $100 \%$ of the corpus texts.

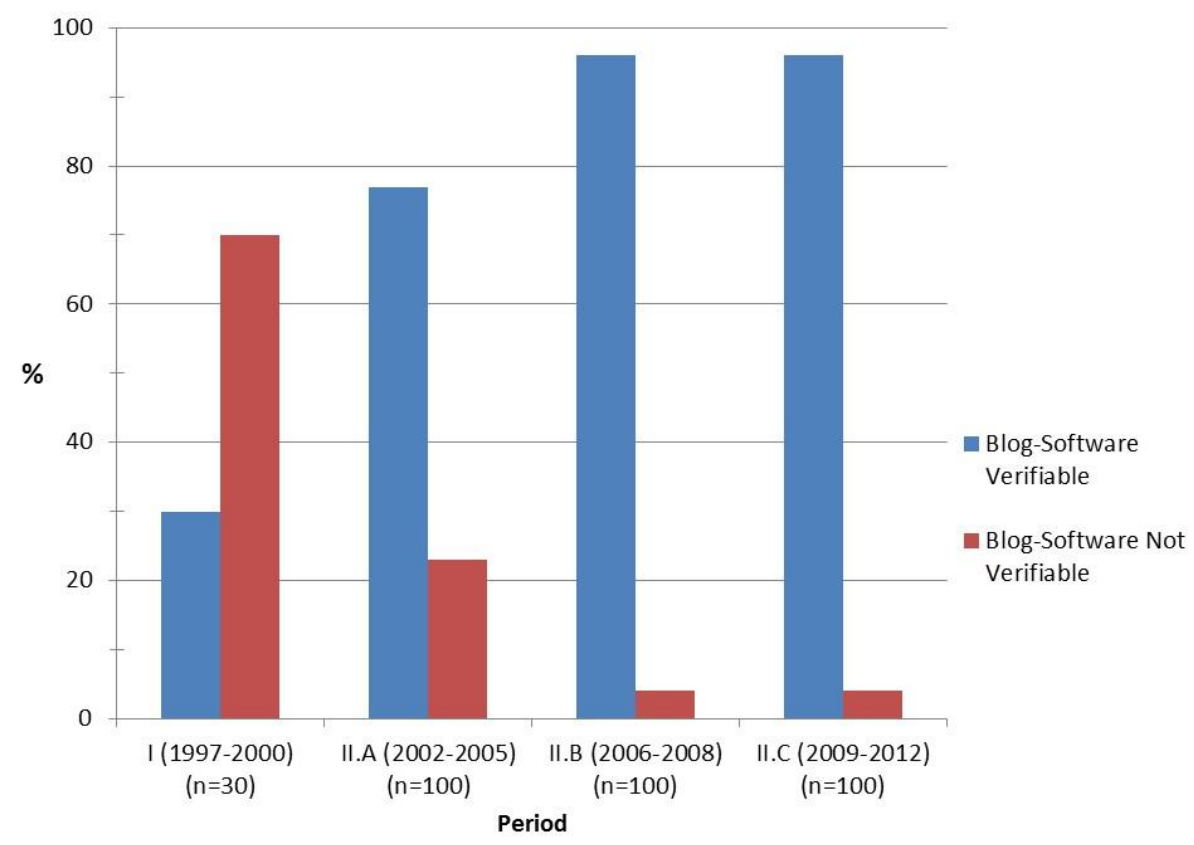

Diagram 4: Use of Blog-Software (n:blog-pages)

\subsubsection{Sharing Experience-Postings}

The beginnings of the personal weblog are characterised by a rapid spread of the posting genre sharing experience. Postings of this category narrate and reflect on a subjectively important event in the author's life as the typical example in (6) illustrates:

(6) BOOM!

I was sitting at home Friday evening and then a suprise power outage occured. This is weird because NES never loses power. The power came back on for a few minutes and then went out again. This time it didn't come back on again. Well I'm bored. What to do without TV? I know, I'll vacuum. That was dumb since there was no power. [...] Everybody in the neighborhood is walking outside asking if they had power and exchanging what nots. As my neighbors were leaving to have drinks elsewhere I saw this huge explosion on the other side of the interstate.

[...] I call 911 to report what I saw and it turns out that a utility pole that caught fire and the transformer on top blew up. [...] I realized a couple of things during this power outage. I like electricity and beer keeps colder with it.

(Chris Loyd 2-5, period II.B)

Sharing experience postings are usually longer than, for instance, filter postings and typically contain numerous cohesive ties such as the recurrence of power, proforms (this, they) and subjunctions (because, as) in (6), which underline the impression of a coherent narrative unit. Additionally, these postings are highly subjective ( $I$ occurs nine times in (6)) and exhibit a dual structure of narration and reflection. Chris Loyd introduces the reflection section with $I$ 
realized. In some cases, this passage is considerably extended and also contains more general reflections. Postings of this genre seem to deal with all topics everyday life has to offer.

\subsubsection{Weblog and Personal Weblog: Genre Split}

The spread of sharing experience-postings fuels the debate about what constitutes the weblog as a genre. Members of the first blogging community reject the practices of the newcomers as Blood recounts some years later: "These are diaries, not Weblogs. Weblogs are about links." (Blood 2004: 54; cf. also McNeill 2009: 153) This phase leads to establishing the new genre label personal weblog, which stresses both the weblog-ancestry and the new quality of these texts. The emergence of the personal weblog thus involves a genre split well reflected in the community's discourse. Figure 4 below illustrates this process and also highlights the second layer of the communication form (see Table 1) that becomes relevant for personal weblogs as opposed to weblogs.

The end of this process cannot be dated with certainty due to a lack of data. As the genre category is part of the blog directory Globe of Blogs launched in 2002, the emergence can be considered completed by 2002 the latest.

\subsubsection{Diary and Personal Weblog: Migration}

The particular importance of the diary for the personal weblog has been highlighted already (see, e. g., Kitzmann 2004; Herring/Paollilo 2006; McNeill 2005, 2009; Karlsson 2006; Yus 2011). There are several reasons to assume a process of migration: Some corpus texts have been labeled diary or journal (e. g. andrewf my life, II.A and SanityWarp, II.B), and some blogsystems such as LiveJournal build on the diary-metaphor (cf. boyd 2004). The influence of the diary is especially notable regarding the posting genre sharing experience. The standards of authenticity ${ }^{26}$ outlined above can be compared to the "contract of autobiography" (Kitzmann 2004: 12) assumed for diary-writing. As "the diary may always have been a communicative genre" (Karlsson 2006: 8-9), the potential publicity of the WWW may not constitute a radical caesura in this migration process. However, extending the potential audience to utter strangers, indeed, transforms some features of the ancestor genre, giving the new genre a new quality.

The online diary can be assumed to constitute a possible intermediate stage in this migration process, which is also illustrated in Figure 4. Online Diaries date back to 1995 (cf. Serfaty 2004: 19) and express an even stronger connection to their offline ancestor by their genre label. Apparently, they contrast to personal weblogs in implementing the page-paradigm, i. e. setting a new page for each posting, and lending less importance to readership numbers (cf. Rosenberg 2009: 28; but see McNeill 2005 on the reader-author relation on online diaries).

\footnotetext{
${ }^{26}$ In addition to the remarks made on authenticity, there are some indications that authors of (personal) weblogs follow an ethical code of truthfulness. Rebecca Blood (2002: 117) states for instance: "Publish as fact only what you believe to be true." Blood's code closely mirrors the Gricean quality maxim "Try to make your contribution one that is true." (Grice 1975: 46) An orientation towards this maxim can be detected in a number of corpus texts, e. g., when information is corrected if it turns out to be wrong or no longer up-to-date (cf. Schildhauer 2016: 139f.). Coding the DIABLOC for strategies of staging truthfulness would certainly constitute a promising issue for future research.
} 


\subsubsection{Further Migration Processes}

The posting genre repertoire of the personal weblog is diverse (Diagram 3), containing many more categories than the ones that could have been be described here. For these posting genres, a number of additional offline ancestors can be assumed. Baron (2008: 106) suggests the ancestor talk radio, which could be connected to voicing opinions-postings. Puschmann (2010: 72) additionally assumes ancestors in journalistic genres and a connection between offline and blog reviews appears to be plausible.

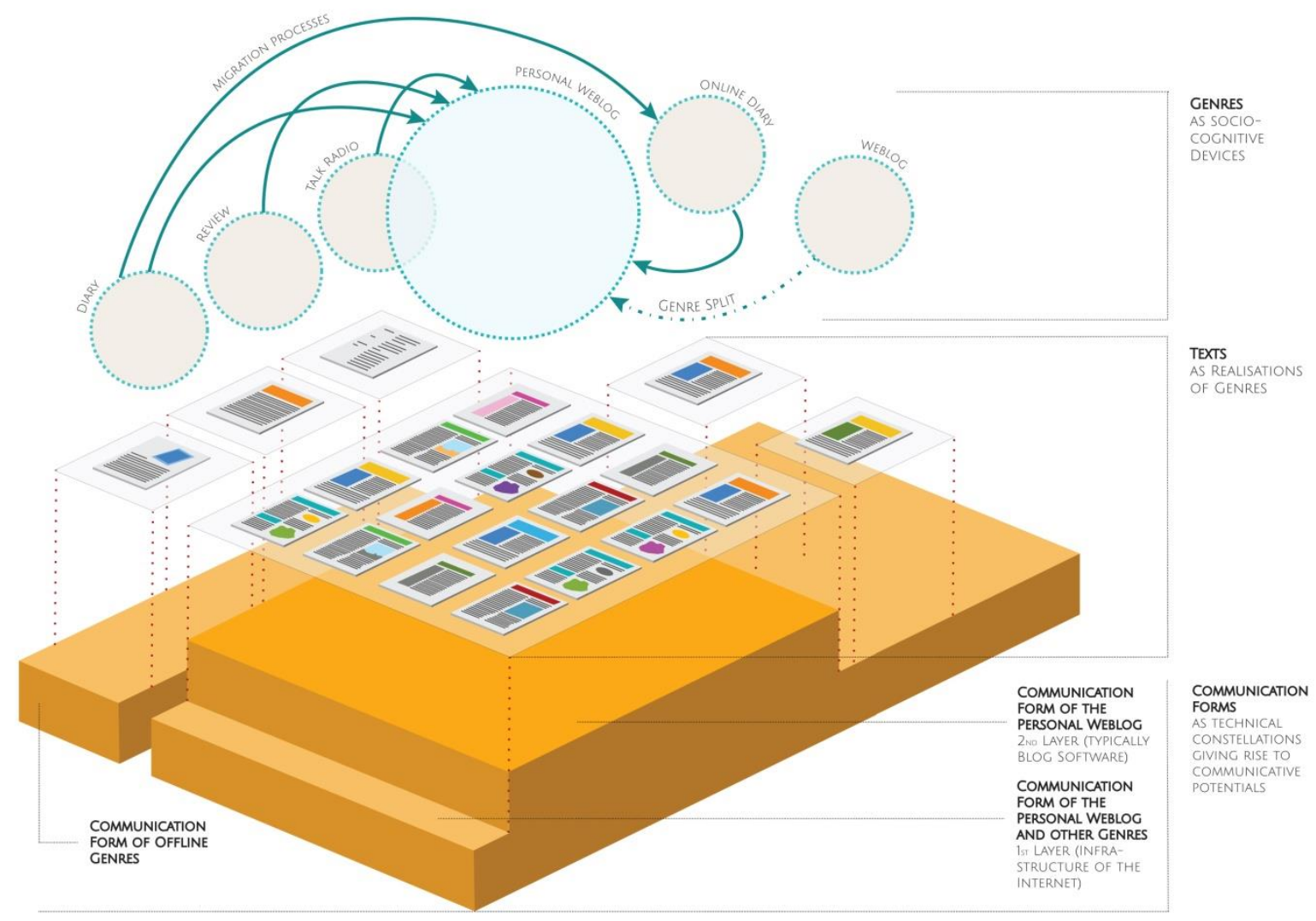

Figure 4: The Personal Weblog in the Context of Other Genres (visualised by J. Pflaeging)

\subsection{Development of Further Blog-Genres (2001 to late 2000s)}

\subsubsection{Consolidation}

The corpus periods II.A and II.B mirror a consolidation of the genre personal weblog. Most importantly, the genre is reflected in the category system of the Globe of Blogs-directory, which indicates its established status. Furthermore, a comparison of period II.A and II.B reveals only minor changes in the frequencies of posting genres (Diagram 3). The fact that playful uses of the established genre appear can be interpreted as another sign of consolidation:

(7) An Offer of Optimism

I don't like to think I'm naive. I prefer to consider myself, instead, an optimist. I like to believe my eagerness to find the hidden answer is what sometimes (lately more often) results in my less than favorable situational hardships. Take my shitty apartment for example. There's barely any plumbing. It's beginning to freeze at night. And a week ago, I found a winged rat had chewed through my loaf 
of bread. [...] This said, I attended the wedding of Sam Hain over the weekend. Sam Hain the Scarecrow Master, the King of Halloween, the Exalted Patriarch of Pumpkins, His Haunted Holiness...

(Dandy Darkly, II.B, additional excerpt 02.11.2009)

At first sight, this posting strongly resembles sharing experience postings in its focus on everyday life. This resemblance is additionally underlined by the high frequency of the pronoun "I" and the occurrence of temporal deictic expressions ("over the weekend"). It is only when a "winged rat" and later "Sam Hain" are mentioned that a reader might infer that it is rather a ghost story which is presented here. (7) is therefore a case of pattern embedding: Patterns of the ghost story-genre (e.g. fictionality, the occurrence of supernatural characters etc.) are embedded into a text which exhibits patterns of the personal weblog and which has been assigned this label by its author. The result is an interesting blend of fictional and non-fictional genre patterns.

\subsubsection{Genre Splits}

While the personal weblog is being consolidated, other blog genres emerge by splitting off from it. The corporate blog, for instance, develops around 2003 (cf. Puschmann 2010: 82-84) out of personal weblogs written by employees with a focus on their work or their company's products (employee blogs, cf. Efimova/Grudin 2007). Employee blogs emerge around 2001 - probably at the same time as science blogs (cf. Fritz 2013: 547).

\subsection{Competition, Variation, Commerce (end of 2000s to 2012)}

\subsubsection{Competition: Social Network Sites}

Both filter- and the update-postings notably ${ }^{27}$ decline after period II.A (Diagram 3). Update postings constitute short summaries of recent events in the author's life which are aimed at keeping friends and family up-to-date. This dramatic decrease is most likely connected to the influence of Social Network Sites such as Facebook and Twitter. Both Status Messages and Tweets are commonly used for updating friends and sharing hyperlinks (see, e. g., Java et al. 2007; Lee 2011). Most fittingly, the decrease of frequency of both posting genres starts in period II.B, shortly after in 2006 Twitter has been launched and Facebook opened to a global audience (cf. boyd/Ellison 2007: 212). Sharing experience does not take part in this development and rather consolidates its position as the core category. It can be assumed that a functional differentiation takes place in period II.B and II.C: Whereas Social Network Sites are used for short update- and filter-postings, personal weblogs are the place for longer and elaborate reflections on single instances. This is also reflected by the significant increase in posting length from period II.B to period II.C in Table 5.28

\footnotetext{
27 This impression is supported by $\varphi_{\mathrm{c} \text { (period, update) }}=0.273(\mathrm{p}<0.0001)$ and $\varphi_{\mathrm{c} \text { (period, filter) }}=0.327(\mathrm{p}<0.0001)$ : wether update- and filter-postings are encountered frequently on blog-pages is strongly dependent on the corpus period focused on.

${ }^{28}$ T-test gives $\mathrm{p}<0.0001$ for II.B vs. II.C.
} 


\begin{tabular}{crrrl}
\hline Period & Min. & Max. & Mean & SD \\
\hline I (1997-2000) & 7.00 & 1796.00 & 208.40 & 403.05 \\
II.A (2002-2005) & 1.00 & 916.00 & 239.40 & 190.76 \\
II.B (2006-2008) & 39.71 & 929.70 & 269.50 & 182.30 \\
II.C (2009-2012) & 9.00 & 1965.00 & 433.67 & 375.85 \\
\hline
\end{tabular}

Table 5: Tokens per Posting and Blog-Page

\subsubsection{Variation}

At the same time, some structural features show an increased scope of variation, as illustrated by Table 6 with regard to the number of images used per posting:

\begin{tabular}{ccccc}
\hline Period & Min. & Max. & Mean & SD \\
\hline I (1997-2000) & 0.00 & 11.39 & 0.99 & 2.89 \\
II.A (2002-2005) & 0.00 & 26.49 & 2.22 & 4.54 \\
II.B (2006-2008) & 0.00 & 49.77 & 4.65 & 7.67 \\
II.C (2009-2012) & 0.00 & 87.59 & 7.37 & 11.56 \\
\hline
\end{tabular}

Table 6: Images in Postings per 1000 Words and Blog-Page

Generally, Table 6 indicates an evolutionary change of an increasing importance of images in personal weblogs. In each period, however, blogs can be found whose entries do not feature any images at all. Therefore, the standard deviation also rises considerably, which indicates an increase in the genre's variation scope.

\subsubsection{Commerce}

The posting genre advertisement also shows a considerable increase towards period II.C:29 Some authors use their leisure activity to advertise their own or third-party products. The personal weblog Baby Blackbird, for instance, blends the posting genres sharing experience and advertisement: While reflecting on her experiences as a mother, the author advertises children's clothes, with sponsors listed in the sidebar. Other personal weblogs in period II.C follow similar strategies (e. g. Bay Area Mommy). Concerning these cases and especially with some authors advertising their own products (e. g. Always Crave Cute), the boundary between the personal weblog and the corporate blog grows increasingly fuzzy.

\section{Conclusions}

In this paper, I pursued a set of related research questions concerning the personal weblog. On the one hand, these questions were treated in their own right in order to contribute to the understanding of the history of the personal weblog as a central genre of the WWW. On the

${ }^{29} \varphi_{\mathrm{c} \text { (period, advertisement) }}=0.226(\mathrm{p}=0.001)$ underlines the interrelation between the time variable and the occurrence of advertisement-postings on blog-pages. 
other hand, these questions served to explore the potentials and limitations of a diachronic approach to web-based genres. The diachronic approach was defined as combining both the analysis of corpus data and historical sources under a time-sensitive perspective. In this last section, I will first address the genre-specific set of questions and then move on to the broader issue.

\subsection{What genre features of the personal weblog can be considered recurrent and stable, and what features have changed over time?}

Mainly based on quantitative data, recurrent features of the personal weblog could be identified, which are also shared by the weblog as its closest ancestor to some extent. Weblogs and personal weblogs are typically kept by a single author. Particularly personal weblogs follow an ideal of immediacy. Weblogs and personal weblogs are oriented towards a code of authenticity and truthfulness of self-representation. Most importantly, the repertoire of posting genres is the same for both complex genres and remains unchanged over all corpus periods.

The repertoire of posting genres also exemplifies the simultaneity of continuity and change: For instance, sharing experience replaces filter as the core posting genre. Additionally, the updates also decline under the influence of Social Network Sites. The changing importance of individual posting genres is also reflected structurally, for instance in the decreasing frequency of external hyperlinks and the increasing mean entry length. As another example of structural change, the mean number of images per entry has been interpreted as an increasing importance of the visual. It has been pointed out that genre change may also involve an increase in a genre's scope of variation if some authors apply established patterns rather than following the change.

\subsection{How does the personal weblog relate to other genres in both on- and offline contexts, particularly concerning the weblog and the diary?}

I paid particular attention to reconstructing the process of genre splitting which has possibly led to the emergence of the personal weblog out of the weblog. Other genre splits have been mentioned with regard to the role of the personal homepage and the emergence of several bloggenres related to the personal weblog. At several points, e. g. considering the page paradigm, this paper could pinpoint traces of the ancestor genres (in this case: most likely the personal homepage), which underlines that genre splitting is a gradual process. Whether later occurrences of patterns of an ancestor genre (for instance, a macro structure similar to personal homepages used on a 2011 personal weblog) should still be regarded as traces of the genre split or, rather, as instances of pattern embedding, must be left open as both scenarios are similarly likely.

I have argued that the logbook, the diary and some other, possibly journalistic genres are linked to the personal weblog by the process of migration. They constitute transmedial points of reference, with their genre knowledge being applied to similar communicative tasks in a new communication form. The paper has also shown, however, that migration also involves a transformation of the genre in the new communication form. The diary, for instance, has undergone changes such as a widening of the potential audience after migrating to the web. 
Furthermore, the paper emphasised the role of newspage and e-zine as likely sources of pattern embedding.

6.3 What phases of development of the personal weblog can be proposed on the grounds of both corpus data and historical documents and how do these relate to other models proposed so far?

This paper suggested four stages, which are compared to other models in Table 7:

\begin{tabular}{|c|c|c|c|}
\hline & Current Study & $\begin{array}{l}\text { Hoffmann (2012: 32- } \\
\text { 34) }\end{array}$ & $\begin{array}{l}\text { Miller/Shepherd } \\
\text { (2009: 266-271) }\end{array}$ \\
\hline $\begin{array}{l}\text { Methods / } \\
\text { Sources }\end{array}$ & $\begin{array}{l}\text { mixed-methods, } \\
\text { corpus texts and } \\
\text { historical sources }\end{array}$ & $\begin{array}{l}\text { interpretation of } \\
\text { historical sources (e. g. } \\
\text { Blood 2003) and } \\
\text { previous studies (e. g. } \\
\text { Herring et al. 2004; } \\
\text { Miller \& Shepherd } \\
\text { 2004) }\end{array}$ & $\begin{array}{l}\text { mainly interpretation } \\
\text { of historical sources } \\
\text { including surveys }\end{array}$ \\
\hline \multirow[t]{4}{*}{ Stages } & $\begin{array}{l}\text { emergence of the } \\
\text { weblog }(1997-1999)\end{array}$ & $\begin{array}{l}\text { simulation (ca. 1996- } \\
\text { 1999) } \\
\text { weblogs as "metasites" }\end{array}$ & $\begin{array}{l}\text { before 1999: } \\
\text { primarily filter blogs }\end{array}$ \\
\hline & $\begin{array}{l}\text { emergence of the } \\
\text { personal weblog } \\
(1999-2001)\end{array}$ & $\begin{array}{l}\text { specialization (ca. } \\
\text { 1999-2002) "induced } \\
\text { by a [sic!] overarching } \\
\text { technological change" } \\
\text { with weblogs } \\
\text { borrowing from other } \\
\text { text genres }\end{array}$ & $\begin{array}{l}\text { 1999-2002(?): "Self- } \\
\text { Disclosure rather } \\
\text { than information } \\
\text { sharing" enabled by } \\
\text { changes in technology }\end{array}$ \\
\hline & $\begin{array}{l}\text { consolidation and } \\
\text { development of } \\
\text { further blog-genres } \\
\text { (2001 to late 2000s) }\end{array}$ & $\begin{array}{l}\text { stratification (ca. } \\
\text { 2002-2005): } \\
\text { development of } \\
\text { different "blog types", } \\
\text { rise of debates about } \\
\text { the purposes of } \\
\text { blogging }\end{array}$ & \multirow[t]{2}{*}{$\begin{array}{l}\text { 2002(?)-2009(?): } \\
\text { blogs on or linked } \\
\text { through Social } \\
\text { Network Sites }\end{array}$} \\
\hline & $\begin{array}{l}\text { competition, } \\
\text { variation and } \\
\text { commerce (end of } \\
2000 \text { s to 2012) }\end{array}$ & $\begin{array}{l}\text { interaction (ca. 2005- } \\
\text { 2011): increasing use } \\
\text { of web } 2.0 \text { features and } \\
\text { blogs extending into } \\
\text { Social Network Sites }\end{array}$ & \\
\hline
\end{tabular}

Table 7: Models of the Development of the Personal Weblog 
The three models differ in several respects:

- While Hoffmann (2012) mostly relies on results of previous studies, Miller/Shepherd (2009) mainly follow an interpretive-rhetorical approach using a variety of historical sources and surveys. The current study complements this approach with the analysis of corpus texts.

- Hoffmann (2012) and Miller/Shepherd (2009) mainly follow Blood's (2000, 2002) claim that first generation weblogs are filter blogs. The current study highlights that other posting genres are present in these years as well.

- The debates among bloggers concerning genre conventions are mentioned both by Hoffmann (2012) and the current study. Here, however, these debates are dated earlier due to a broader basis of historical sources. The emergence of the weblog could be dated more precisely than in Miller/Shepherd (2009).

- In contrast to Hoffmann (2012), the current study underlined the influence of other genres from the first phase onwards.

- Hoffmann (2012) views the launch of blog-software as inducing later developments such as the growing importance of diary-like patterns. Miller/Shepherd (2009) and the current paper interpret the new blog-software rather as a catalyst of a development already in progress. This has implications for a less deterministic modelling of the relation between communication form and genre.

- Hoffmann (2012) offers relatively specific dates for the phases without making transparent where they are derived from. Miller/Shepherd (2009) and the current study refrain from exact dates where only approximations can be given on the basis of the data.

This cursory comparison leads to the general research question:

\subsection{What are the possible benefits and limitations of a diachronic approach to web-based genres?}

A diachronic approach as defined here offers the opportunity of evaluating established views from a different perspective and thereby gaining new insights. In particular, it provides the opportunity to document and corroborate mechanisms of genre change.

However, sometimes the price of this more differentiated view is a loss of clarity (e. g. a loss of a concrete dates). Moreover, the results of a corpus-based study are tightly linked to its research corpus, which includes the possibility of years not covered by corpus data. In the present study, no corpus data was available for the year 2001, which made reconstructing the emergence of the personal weblog more difficult. Compiling reliable corpora of web-based genres will be a challenge for future research as it was for the study reported here.

This paper showed that a diachronic view on a web-based genre such as the personal weblog can highlight recurring features and continued traditions, thereby decreasing the impression of revolutionary dynamics the WWW is most likely to evoke. However, the diachronic perspective does not save this study from the need of being updated as long as the history of the personal weblog continues. "[L]e fleuve de la langue coule sans interruption [...]" (Wunderli 2013: 290). 


\section{Corpus}

The Diachronic Blog Corpus (DIABLOC) cited here is described in detail (and listed in full) on www.pschildhauer.com/corpus.

Bay Area Mommy (2015): Bay Area Mommy period II.C. http://tinyurl.com/baymum-pb [06.01.2017].

Way Back Machine. Internet Archives (1997): Perfect, period I. http://tinyurl.com/perfectweblog [06.01.2017].

Way Back Machine. Internet Archives (1997): Scripting News, period I. http://tinyurl.com/scripting-weblog [06.01.2017].

Way Back Machine. Internet Archives (1998): Camworld, period I. http://tinyurl.com/camworld-weblog [06.01.2017].

Way Back Machine. Internet Archives (1998): Need to Know, period I. http://tinyurl.com/ntkweblog [06.01.2017].

Way Back Machine. Internet Archives (1998): PigDog, period I. http://tinyurl.com/pig-weblog [06.01.2017].

Way Back Machine. Internet Archives (1999): Infosift, period I. http://tinyurl.com/infoshift [06.01.2017].

Way Back Machine. Internet Archives (1999): Linky \& Dinky, period I. http://tinyurl.com/linkydinky [06.01.2017].

Way Back Machine. Internet Archive (2004): All back to mine, period II.A. http://tinyurl.com/allback-pb [06.01.2017].

Way Back Machine. Internet Archives (2005): andrewf my life, period II.A. http://tinyurl.com/andrewf-pb [06.01.2017].

Way Back Machine. Internet Archive (2006): Alone in Tacoma, period II.B. http://tinyurl.com/tacoma-pb [06.01.2017].

Way Back Machine. Internet Archives (2006): Chris Loyd, period II.B. http://tinyurl.com/chrisloyd-pb [06.01.2017].

Way Back Machine. Internet Archives (2007): SanityWarp, period II.B. http://tinyurl.com/sanity-pb [06.01.2017].

Way Back Machine. Internet Archives (2008): Dandy Darkly, period II.B. http://tinyurl.com/dandy-pb [06.01.2017].

Way Back Machine. Internet Archives (2012): Always Crave Cute, period II.C. http://tinyurl.com/cravecute-pb [06.01.2017].

Way Back Machine. Internet Archives (2012): Baby Blackbird, period II.C. http://tinyurl.com/baby-pb [06.01.2017].

\section{References}

Askehave, Inger/Nielsen, Anne Ellerup (2005): "Digital Genres. A Challenge to Traditional Genre Theory". Information Technology \& People 2/18: 120-141.

Baron, Naomi S. (2008): Always on: Language in an Online and Mobile World. Oxford: Oxford University Press.

Barrett, Cameron (1999a): “Anatomy of a Weblog”. Camworld. http://tinyurl.com/barrett99a [26.07.2016]. 
Barrett, Cameron (1999b): "More about Weblogs". Camworld. http://tinyurl.com/barrett99b [26.07.2016].

Bateman, John A. (2011): Multimodality and Genre. A Foundation for the Systematic Analysis of Multimodal Documents. Basingstoke: Macmillan.

Baumer, Eric/Sueyoshi, Mark/Tomlison, Bill (2008): "Exploring the Role of the Reader in the Activity of Blogging". In: Burnett, Margaret (ed.): CHI 2008: The 26th Annual CHI Conference on Human Factors in Computing Systems. New York, ACM: 1111-1120.

Bausch, Paul et al. (2002): We blog: Publishing online with weblogs. New York: Wiley.

Benton, Michael (2006a): "Why I blog: Part 1". Reconstruction 6 http://tinyurl.com/benton06a [15.11.2016].

Benton, Michael (2006b): "Why I blog: Part 2". Reconstruction 6 (4). http://tinyurl.com/benton06b [15.11.2016].

Blood, Rebecca (2000): "Weblogs: A history and perspective". Rebecca's Pocket. http://tinyurl.com/blood2000 [26.07.2016].

Blood, Rebecca (2002): The Weblog Handbook: Practical Advice on Creating and Maintaining your Blog. Cambridge (MA): Perseus.

Blood, Rebecca (2004): "How Blogging Software Reshapes the Online Community". Communications of the ACM 12/47: 53-55.

Bolter, Jay David/Grusin, Richard (2001): Remediation. Understanding New Media. Cambridge (MA): MIT Press.

Boyd, Dana. (2004): "Broken Metaphors: Blogging as Liminal Practice". Draft. http://tinyurl.com/boyd2004 [26.07.2016].

Boyd, Dana/Ellison, Nicole (2007): "Social Network Sites: Definition, History, and Scholarship". Journal of Computer-Mediated Communication 1/13: 210-230.

Brock, Alexander (2009): „Zur Variation komischer Textsorten: der Fall britischer Fernsehcomedies“. In: Lenz, Friedrich (ed.): Schlüsselqualifikation Sprache: Anforderungen Standards - Vermittlung. Frankfurt a. M., Lang: 235-253. (= Forum Angewandte Linguistik 50).

Brock, Alexander (2013): "On the Corruption of Text Types: The Cases of Comedy and Readers' Commentaries in Online Newspapers". In: Ammermann, Anne et al. (eds.): Facets of Linguistics. Frankfurt a. M., Lang: 63-74. (= Hallesche Sprach- und Textforschung 12).

Brock, Alexander/Schildhauer, Peter (forthc.): "Defining Communication Form: A Concept Revisited". In: Brock, Alexander/Schildhauer, Peter (eds.): Communication Forms and Communicative Practices: New Perspectives on Communication Forms, Affordances and What Users Make of Them. Frankfurt a. M.: Lang.

Brook, Donald (2002): "Why I Fucking Hate Weblogs!”. Why I Fucking Hate Weblogs. http://tinyurl.com/hateweblg [26.07.2016].

Chandler, Daniel (1998): "Personal Homepages and the Construction of Identities on the Web". Way Back Machine. http://tinyurl.com/chandler98arc [26.07.2016].

Crystal, David (2006): Language and the Internet. Cambridge: Cambridge University Press.

Devitt, Amy J. (2009): "Re-fusing Form in Genre Study". In: Giltrow, Janet/Stein, Dieter (eds.): Genres in the Internet: Issues in the Theory of Genre. Amsterdam/Philadelphia, Benjamins: $27-47$.

Dunning, Ted (1993): "Accurate Methods for the Statistics of Surprise and Coincidence". Computational Linguistics 1/19: 61-74. 
Dürscheid, Christa (2005). „Medien, Kommunikationsformen, kommunikative Gattungen”. Linguistik online 1/22: 1-16.

Efimova, Lilia/Grudin, Jonathan (2007): “Crossing Boundaries: A Case Study of Employee Blogging”. http://tinyurl.com/zkzycnn [no longer available].

Efimova, Lilia (2009): Passion at Work: Blogging Practices of Knowledge Workers. Dissertation. Enschede: Novay.

Ess, Charles/AoIR Ethics Working Committee (2002): "Ethical Decision-making and Internet Research: Recommendations from the AoIR Ethics Working Committee". Aoir ethics document. http://tinyurl.com/87swmuj [26.07.2016].

Fritz, Gerd (2013): Dynamische Texttheorie. Gießen: Gießener Elektronische Bibliothek. (=Linguistische Untersuchungen 5).

Galloway, Alexander/Thacker, Eugene (2004): "Protocol, Control and Networks". Grey Room 17: 6-29.

Giltrow, Janet (2013): “Genre and Computer-mediated Communication". In: Herring, Susan/Stein, Dieter/Virtanen, Tuija (eds.): Pragmatics of Computer-mediated Communication. Berlin, de Gruyter: 717-737. (= Handbooks of Pragmatics 9).

Giltrow, Janet/Stein, Dieter (2009a): "Genres in the Internet: Innovation, Evolution, and Genre Theory". In: Giltrow, Janet/Stein, Dieter (eds.): Genres in the Internet: Issues in the Theory of Genre. Amsterdam/Philadelphia, Benjamins: 1-26. (= Pragmatics \& Beyond new series 188).

Giltrow, Janet/Stein, Dieter (eds.) (2009b): Genres in the Internet: Issues in the Theory of Genre. Amsterdam/Philadelphia: Benjamins. (= Pragmatics \& Beyond new series 188).

Glaser, Barney G./Holton, Judith (2004): "Remodeling Grounded Theory". Forum: Qualitative Social Research, 2/5. http://tinyurl.com/glaserholton2004 [26.07.2016].

Grice, Herbert Paul (1975): "Logic and Conversation". In: Cole, Peter/Morgan, Jerry. L. (eds.): Syntax and Semantics: Vol. 3. Speech Acts. London, New York, Academic Press: 41-58.

Herring, Susan et al. (2004): "Bridging the Gap: A Genre Analysis of Weblogs". Proceedings of the 37th Hawai'i International Conference on System Sciences (HICSS-37). http://tinyurl.com/herrscheidt04 [26.07.2016].

Herring, Susan et al. (2005): "Weblogs as a Bridging Genre". Information Technology \& People 2/18: 142-171.

Herring, Susan/Paolillo, John C. (2006): “Gender and Genre Variation in Weblogs". Journal of Sociolinguistics 4/10: 439-459.

Herring, Susan et al. (2006): “A Longitudinal Content Analysis of Weblogs: 2003-2004”. In: Mark Tremayne (Ed.) (in press), Blogging, Citizenship and the Future of Media. London: Routledge. http://tinyurl.com/herring2006 [26.07.2016].

Heyd, Theresa (2009): “A Model for Describing 'New' and 'Old' Properties of CMC Genres: The Case of Digital Folklore”. In: Giltrow, Janet/Stein, Dieter (eds.): Genres in the Internet: Issues in the Theory of Genre. Amsterdam/Philadelphia, Benjamins: 239-262. (= Pragmatics \& Beyond new series 188).

Hoffmann, Christian R. (2012): Cohesive Profiling: Meaning and Interaction in Personal Weblogs. Amsterdam/Philadelphia: Benjamins. (= Pragmatics \& Beyond new series 219).

Holly, Werner (2011): „Medien, Kommunikationsformen, Textsortenfamilien“. In: Habscheid, Stephan (ed.): Textsorten, Handlungsmuster, Oberflächen: Linguistische Typologien der Kommunikation. Berlin/New York: de Gruyter: 144-163. 
Hourihan, Meg (2002): "What We're Doing When We Blog". Oreilly. http://tinyurl.com/megnut2002 [26.07.2016].

Hutchby, Ian (2001): “Technologies, Texts and Affordances". Sociology 2/35: 441-456.

Java, Akshay et al. (2007): "Why we Twitter: Understanding Microblogging Usage and Communities". UMBC ebiquity. http://tinyurl.com/javaetal2007 [26.07.2016].

Karlgren, Jussi (2011): "Conventions and Mutual Expectations: Understanding Sources for Web Genres". Mehler, Alexander/Sharoff, Serge/Santini, Marina (eds.): Genres on the Web: Computational Models and Empirical Studies. Dordrecht, Springer: 33-46. (= Text, Speech and Language Technology 42).

Karlsson, Lena (2006): “Acts of Reading Diary Weblogs”. Human IT 2/8: 1-59.

Kitzmann, Andreas (2004): Saved from Oblivion: Documenting the Daily from Diaries to Web Cams. New York: Lang.

Lee, Carmen K. M. (2011): "Micro-blogging and Status Updates on Facebook: Texts and Practices". In: Thurlow, Crispin/Mroczek, Kristine R. (eds.): Oxford Studies in Sociolinguistics: Digital Discourse. Language in the New Media. Oxford, Oxford University Press: $110-128$.

Lemke, Jay L. (1999): "Specifying Genres". Typology, Topology, Topography: Genre Semantics. http://tinyurl.com/lemke99archive [26.07.2016].

Lomborg, Stine (2009): "Navigating the Blogosphere: Towards a Genre-based Typology of Weblogs". First Monday 5/14. http://tinyurl.com/lomborg2009 [26.07.2016].

Lomborg, Stine (2014): Social Media, Social Genres: Making Sense of the Ordinary. New York: Routledge.

Luginbühl, Martin (2014): "Genre Profiles and Genre Change: The Case of TV News". In: Androutospoulos, Jannis (ed.): Mediatization and Sociolinguistic Change. Berlin, de Gruyter: 305-330. (= linguae \& litterae 36).

Mauranen, Anna (2013): "Hybridism, Edutainment, and Doubt: Science Blogging Finding its Feet". Nordic Journal of English Studies 1/12: 7-36.

McNeill, Laurie (2009): "Brave New Genre, or Generic Colonialism? Debates over Ancestry in Internet Diaries". In: Giltrow, Janet/Stein, Dieter (eds.): Genres in the Internet: Issues in the Theory of Genre. Amsterdam/Philadelphia, Benjamins: 143-161. (= Pragmatics \& Beyond new series 188).

Meiler, Matthias (2013): „Kommunikationsformenadressen oder: Prozeduren des Situationsvollzugs am Beispiel von Weblogs“. Zeitschrift für Angewandte Linguistik 2/59: 51-106.

Miller, Carolyn (1984): “Genre as Social Action”. Quarterly Journal of Speech 2/70: 151-167. Miller, Carolyn/Shepherd, Dawn (2004): "Blogging as Social Action: A Genre Analysis of the Weblog". Into the Blogosphere. http://tinyurl.com/miller04 [26.07.2016].

Miller, Carolyn/Shepherd, Dawn (2009): "Questions for Genre Theory from the Blogosphere". In: Giltrow, Janet/Stein, Dieter (eds.): Genres in the Internet: Issues in the Theory of Genre. Amsterdam/Philadelphia, Benjamins: 263-290. (= Pragmatics \& Beyond new series).

Myers, Greg (2010): The Discourse of Blogs and Wikis. London: Continuum.

Nardi, Bonnie/Schiano, Diane/Gumbrecht, Michelle (2004): "Blogging as Social Activity, or, Would You Let 900 Million People Read Your Diary?” In: Herbsleb, Jim/Olson, Gary (eds.): Proceedings of the 2004 ACM Conference on Computer-Supported Cooperative Work. New York, ACM: 222-231. 
Nardi, Bonnie et al. (2004): "Why We Blog". http://tinyurl.com/nardietal2004 [no longer available].

McNeill, Laurie (2005): "Genre Under Construction: The Diary on the Internet". language@internet 2. http://www.languageatinternet.org/articles/2005/120 [26.07.2016].

Puschmann, Cornelius (2010): The Corporate Blog as an Emerging Genre of Computermediated Communication: Features, Constraints, Discourse Situation. Göttingen: Universitätsverlag Göttingen. (= Göttinger Schriften zur Internetforschung 7).

Puschmann, Cornelius (2013): "Blogging". In: Herring, Susan/Stein, Dieter/Virtanen, Tuija (eds.): Pragmatics of Computer-mediated Communication. Berlin, de Gruyter: 75-100. (= Handbooks of Pragmatics 9).

Rosenberg, Scott (2009): Say Everything: How Blogging Began, What It's Becoming, and Why It Matters. New York: Crown.

Rosenberg, Scott (2010): "Postscript: Four Cases for the Persistence of Blogging". Say everything. How blogging began, what it's becoming, and why it matters. http://tinyurl.com/23ccksb [26.07.2016].

Sandig, Barbara (2000): „Text als prototypisches Konzept.” In: Mangasser-Wahl, Martina (ed.): Prototypentheorie in der Linguistik: Anwendungsbeispiele - Methodenreflexion Perspektiven. Tübingen, Stauffenburg: 93-112.

Santini, Martina/Mehler, Alexander/Sharoff, Serge (2011): "Riding the Rough Waves of Genre on the Web: Concepts and Research Questions". In: Mehler, Alexander/Sharoff, Serge/Santini, Marina (eds.): Genres on the Web: Computational Models and Empirical Studies. Dordrecht, Springer: 3-30.

Schildhauer, Peter (2016): The Personal Weblog: A Linguistic History. Frankfurt a.M.: Lang.

Schryer, Catherine (1993): "Records as Genre". Written Communication 2/10: 200-234.

Serfaty, Viviane (2004): The Mirror and the Veil: An Overview of American Online Diaries and Blogs. Amsterdam: Rodopi.

Stöckl, Hartmut (2010): „Textsortenentwicklung und Textverstehen als Metamorphosen - Am Beispiel der Werbung“. In: Stöckl, Hartmut/Grösslinger, Christian (eds.): Mediale Transkodierungen: Metamorphosen zwischen Sprache, Bild und Ton. Heidelberg, Winter: 145-172.

Thaler, Verena (2007): „Mündlichkeit, Schriftlichkeit, Synchronität: Eine Analyse alter und neuer Konzepte zur Klassifizierung neuer Kommunikationsformen“. Zeitschrift für germanistische Linguistik 1-2/35: 146-181.

Viégas, Fernanda B. (2005): "Bloggers' Expectations of Privacy and Accountability: An Initial Survey". Journal of Computer-Mediated Communication 3/10. http://jcmc.indiana.edu/vol10/issue3/viegas.html [26.07.2016].

Winer, Dave (2001): "The History of Weblogs". Userland Software. http://tinyurl.com/winer01 [26.07.2016].

Winer, Dave (2003): “What Makes a Weblog a Weblog?". Weblogs at Harvard Law. http://tinyurl.com/winer03b [26.07.2016].

Wunderli, Peter (ed.) (2013): Cours de linguistique générale. Tübingen: Narr.

Yus, Francisco (2011): Cyberpragmatics: Internet-mediated Communication in Context. Amsterdam/Philadelphia: Benjamins. 